\title{
Beta-irradiation used for systemic radioimmunotherapy induces apoptosis and activates apoptosis pathways in leukaemia cells
}

Claudia Friesen ${ }^{1}$, Annelie Lubatschofski ${ }^{1}$, Jörg Kotzerke², Inga Buchmann², Sven N. Reske², Klaus-Michael Debatin¹

1 University Children's Hospital, Ulm, Germany

2 Department of Nuclear Medicine, University of Ulm, Ulm, Germany

Published online: 26 July 2003

(C) Springer-Verlag 2003

Eur J Nucl Med Mol Imaging (2003) 30:1262

DOI 10.1007/s00259-003-1314-y

The online version of the original article can be found at http://dx.doi.org/10.1007/s00259-003-1216-Z

Eur J Nucl Med Mol Imaging (2003)

DOI 10.1007/s00259-003-1216-z

In the Materials and methods section, under the heading "Western blot analysis", "rabbit anti-Bel- $\mathrm{X}_{3 / 2}$ " should read "rabbit anti-Bcl- $\mathrm{x}_{\mathrm{S} / \mathrm{L}}$ ".

Klaus-Michael Debatin ( $\bullet$ )

University Children's Hospital, Prittwitzstrasse 43, 89075 Ulm,

Germany

e-mail: klaus-michael.debatin@medizin.uni-ulm.de

Tel.: +49-731-50027700, Fax: +49-731-50026681 